\title{
Application of perovskite quantum dots in carrier redistribution in III-V multijunction solar cells with luminescent coupling effect
}

\author{
Bernice Mae Yu Jeco-Espaldon $\odot$, a,b,c,* Haibin Wang $\odot,{ }^{b}$ \\ Achilles E. Espaldon, ${ }^{\text {d Takaya Kubo, }{ }^{\text {bd }} \text { Hiroshi Segawa, }}$ \\ Nazmul Ahsan $\odot,{ }^{b, d}$ and Yoshitaka Okada $\oplus^{b, d}$ \\ ${ }^{a}$ The University of Tokyo, Graduate School of Engineering, Department of Urban Engineering, \\ Tokyo, Japan \\ ${ }^{\mathrm{b}}$ The University of Tokyo, Research Center for Advanced Science and Technology, \\ Tokyo, Japan \\ ${ }^{\mathrm{c}}$ University of Santo Tomas, Electronics Engineering Department, Faculty of Engineering, \\ Manila, Philippines \\ ${ }^{\mathrm{d}}$ The University of Tokyo, Graduate School of Engineering, Department of Advanced \\ Interdisciplinary Studies, Tokyo, Japan
}

\begin{abstract}
The luminescent coupling effect in a multijunction solar cell is known to help achieve current matching among subcells through carrier redistribution. We demonstrate the carrier redistribution in III-V multijunction solar cell devices using a moisture-resistant, all-inorganic perovskite quantum dot (PQD) film. This hydrophobic PQD film was applied on a full III-V multijunction solar cell device. This successfully demonstrated current redistribution vertically, shown by the increased current collection in the lower bandgap subcells, and laterally, as observed from improved current collection homogeneity in the lower bandgap subcell adjacent to the higher bandgap subcell where the luminescence originated. (C) The Authors. Published by SPIE under a Creative Commons Attribution 4.0 Unported License. Distribution or reproduction of this work in whole or in part requires full attribution of the original publication, including its DOI. [DOI: 10 .1117/1.JPE.10.042005]
\end{abstract}

Keywords: all-inorganic perovskite; laser beam induced current; luminescent coupling; mixed halide; multi-junction solar cell.

Paper 20043SS received May 25, 2020; accepted for publication Sep. 28, 2020; published online Oct. 16, 2020.

\section{Introduction}

The III-V multi-junction solar cells (MJSCs) currently hold the best research cell efficiency record of $47.1 \%$ under concentrated sunlight. ${ }^{1}$ To further increase this, the current produced among its subcells should be as matched as possible. In experimental devices, current matching among series-constrained III-V MJSC subcells can be naturally achieved through the luminescent coupling (LC) effect. The LC effect is known as the reabsorption of photons emitted from a higher bandgap subcell to a lower bandgap subcell. ${ }^{2-5}$ Previous studies have reported that when this effect is made stronger through controlled external irradiation upon a higher bandgap subcell, larger current can be produced in the lower bandgap subcell. ${ }^{6-15}$ However, the LC efficiency was found to saturate within $60 \%$ to $70 \%$ of radiative emission in the higher bandgap subcell. ${ }^{16}$ The use of metal halide perovskite quantum dots (PQDs) could be a cost-effective way to enhance photon emission toward the current-limiting cell. Recently, composition-tunable metal halide PQDs were reported as candidate materials for producing high-efficiency photovoltaic devices. ${ }^{17,18}$ In particular, all-inorganic cesium lead halide $\left(\mathrm{CsPbX}_{3}\right)$ PQDs were observed to have higher absorption coefficients, narrower emission wavelengths, higher photoluminescence (PL) quantum yields, and better oxidation resistance than methylammonium lead halide $\left(\mathrm{CH}_{3} \mathrm{NH}_{3} \mathrm{PbX}_{3}\right)$ PQDs. ${ }^{19-29}$

*Address all correspondence to Bernice Mae Yu Jeco-Espaldon, yujeco@env.t.u-tokyo.ac.jp 
The goal of this work was to demonstrate current matching among III-V MJ subcells using moisture-stable $\mathrm{CsPbX}_{3}$ PQDs applied on full III-V MJSC devices limited by a lower bandgap subcell. When current matching among MJ subcells is achieved, the MJSC conversion efficiency can be increased further. This approach was also an attempt to enhance the LC effect homogeneity in a current-limiting subcell through photopassivation by the PQD layer. Attaining this could help maximize the lifespan of MJSCs. ${ }^{11}$

\section{Methodology}

\subsection{Perovskite Quantum Dot Synthesis}

$\mathrm{CsPbX}_{3}(\mathrm{X}=\mathrm{Br}$ and I) PQDs were synthesized using the methods reported in Refs. 25 and 26. The same process reported in Ref. 27 was used to prepare the cesium (Cs)-oleate precursor solution and for synthesis in the reaction flask (RF). The synthesis temperature was set at $170^{\circ} \mathrm{C}$ to produce $\sim 8-\mathrm{nm}^{25}$ to $9.5-\mathrm{nm}^{26} \mathrm{PQD}$ nanocrystals. The synthesized PQDs were diluted in hexane to achieve a $5-\mathrm{mg} / \mathrm{mL} \mathrm{CsPbI}_{2.5} \mathrm{Br}_{0.5} \mathrm{PQD}$ solution. The detailed procedure of the $\mathrm{CsPb}_{2.5} \mathrm{Br}_{0.5} \mathrm{PQD}$ solution preparation can be found in Appendix A.

\subsection{Perovskite Quantum Dot-Cyclic Olefin Copolymer Solution}

Perovskite materials, by themselves, are known to be easily degraded by moisture; hence, their performance as photonic materials easily decline over a short period of time, from a few weeks to a few minutes under typical atmospheric conditions. ${ }^{30-38}$

To protect the PQDs from humidity, polymer matrices can be used. Polymer matrices can be made from one or a combination of materials from the group consisting of polystyrene (PS), polycarbonate $(\mathrm{PC})$, cellulose acetate $(\mathrm{CA})$, polyvinyl chloride (PVC), polyvinylidene fluoride (PVDF), polyurethane (PU), polymethyl methacrylate (PMMA), polyvinyl alcohol (PVA), polyethylene oxide (PEO), polylactic acid (PLA), acrylonitrile butadiene styrene (ABS), polymaleic anhydride-alt-1-octadecene (PMA), and polynitriles. ${ }^{39-44}$ Aside from these, amorphous thermoplastics such as cyclic olefin copolymers (COCs) are known to be moisture-resistant ${ }^{45,46}$ and are transparent to wavelengths beyond $300 \mathrm{~nm}^{47,48}$ for about 88\%, as shown in Fig. 1(a). Figure 1(a) shows the light transmission spectrum of the COC film as found in the manufacturer's datasheet. ${ }^{48}$ Experimentally, COC was found to be transparent to wavelengths between 200 and $1000 \mathrm{~nm}$ by $91 \%$, as shown in Fig. 1(b). This was derived from the reflectance measurements of COC on a quartz substrate. The reflectance measurements were obtained using a commercial ultraviolet (UV)-visible light spectrophotometer. It also has a refractive index of 1.5, making it optically compatible with III-V optoelectronic materials used in solar cell fabrication. Solar cell devices are designed to absorb UV, visible, and infrared (IR) wavelengths from the sun and are made of III-V semiconductors typically with refractive indices of more than 2.0 for III-V
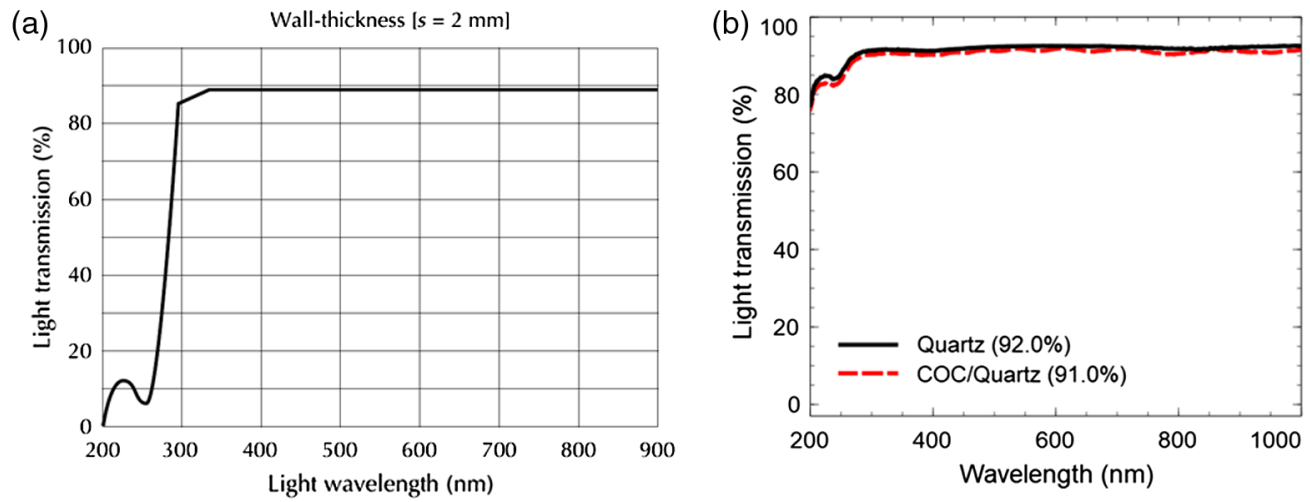

Fig. 1 The transmission spectrum of TOPAS ${ }^{\circledR} \mathrm{COC}$, which was used in the PQD-COC mixture (a) from the manufacturer's specification sheet ${ }^{48}$ and (b) from reflectance measurement. 
materials and more than 1.5 for II-VI materials. ${ }^{49}$ Because of its suitable optical properties and its capability to protect perovskite materials from moisture, this amorphous thermoplastic film was used as the $\mathrm{CsPb}_{2.5} \mathrm{Br}_{0.5} \mathrm{PQD}$ encapsulant by mixing.

COC pellets dissolved in cyclohexane $\left(\mathrm{C}_{6} \mathrm{H}_{12}\right)$ were added to the synthesized $\mathrm{CsPb}_{2.5} \mathrm{Br}_{0.5}$ $\mathrm{PQD}$ solution before substrate dip coating. In this work, about $50-\mathrm{mg} / \mathrm{mL}$ COC dissolved in $\mathrm{C}_{6} \mathrm{H}_{12}$ by ultrasonic bath were mixed with at least $10-\mathrm{mg} / \mathrm{mL} \mathrm{CsPbI}{ }_{2.5} \mathrm{Br}_{0.5}$ PQDs dispersed in hexane $\left(\mathrm{C}_{6} \mathrm{H}_{14}\right)$ to form moisture-robust $\mathrm{PQD}$ films on a target substrate. Considering $\mathrm{C}_{6} \mathrm{H}_{12}$ and $\mathrm{C}_{6} \mathrm{H}_{14}$ volatilities, only a rough estimate of the solution concentration at the time of preparation can be made, based on the measured masses of the pure COCs and $\mathrm{CsPbI}_{2.5} \mathrm{Br}_{0.5}$ PQDs and the injected volumes of $\mathrm{C}_{6} \mathrm{H}_{12}$ and $\mathrm{C}_{6} \mathrm{H}_{14}$, respectively. The COC in $\mathrm{C}_{6} \mathrm{H}_{12}$ and PQD in $\mathrm{C}_{6} \mathrm{H}_{14}$ solutions were mixed at a 1:1 proportion before dip coating the III-V MJSC samples. Hence, the approximate concentrations of each solution in the mixture were effectively halved. Concentrations of $\mathrm{COC}$ in $\mathrm{C}_{6} \mathrm{H}_{12}$ and $\mathrm{PQD}$ in $\mathrm{C}_{6} \mathrm{H}_{14}$ became 25 and $5 \mathrm{mg} / \mathrm{mL}$, respectively. The MJSCs dipped into the $\mathrm{PQD}-\mathrm{COC}$ solution were commercial, third-generation, terrestrial grade $0.31 \mathrm{~cm}^{2} \mathrm{InGaP} / \mathrm{GaAs} / \mathrm{Ge} 3 \mathrm{JSC}$ s samples. These samples were mounted on copper plate and were partially encapsulated. Each of the samples is connected to a bypass diode.

In the past, it was found that the optimal withdrawal speed of GaAs, a III-V material, to produce optically smooth and emissive films was $5 \mathrm{~mm} / \mathrm{s}$, where the values tested were between 1 and $20 \mathrm{~mm} / \mathrm{s}^{27}$ In dip coating, the withdrawal speed is the most critical parameter that affects both the film thickness and its quality. ${ }^{50,51}$ On the other hand, the number of dipping cycles was fixed at 5 times.

\subsection{Electro-optical Characterization}

The dip-coated MJSC samples were evaluated through a laser beam induced current (LBIC) mapping method at room temperature. Here each subcell was made current limiting and subjected to either LC effect excitation or direct laser irradiation. ${ }^{8}$ These measurements were validated through external quantum efficiency $(\mathrm{EQE})$ and current-voltage $(J-V)$ characteristics measurements.

\subsubsection{Laser beam induced current mapping}

To acquire the spatial distribution profile of photocurrent produced in subcells at the various conditions listed in Table 1, the 3JSC samples were subjected to the LBIC mapping method. Here continuous LED biases were used to make a specific 3JSC subcell current limiting. This was done to ensure that there would be no change of current-limiting subcell during the LBIC measurements.

The InGaP photocurrent collection maps were acquired by switching on continuous 780-, 970-, and 1550-nm LEDs at the same time. Their intensities are summarized in Table 1, condition 1. In this condition, a 450-nm pulsed laser was used to excite the InGaP top cell. Then the GaAs LC current collection maps were obtained by switching on continuous 440-, 970-, and 1550-nm LEDs (condition 2), while a 450-nm modulated laser excited InGaP. Since there was no

Table 1 Illumination settings for measuring the LBIC maps from InGaP/GaAs/Ge 3JSC samples.

\begin{tabular}{|c|c|c|c|c|c|c|}
\hline \multirow[b]{2}{*}{ Condition } & \multicolumn{5}{|c|}{ Continuous LED intensity, $P_{\text {LED }}\left(\mathrm{mW} / \mathrm{cm}^{2}\right)$} & \multirow{2}{*}{$\begin{array}{c}\text { Pulsed laser } \\
\text { wavelength, } \lambda_{\text {laser }}(\mathrm{nm})\end{array}$} \\
\hline & $440 \mathrm{~nm}$ & $660 \mathrm{~nm}$ & $780 \mathrm{~nm}$ & $970 \mathrm{~nm}$ & $1550 \mathrm{~nm}$ & \\
\hline 1. InGaP (top) & off & off & 140.1 & 31.4 & 4.2 & 450.0 \\
\hline 2. InGaP-to-GaAs LC & 167.2 & off & off & 31.4 & 4.2 & 450.0 \\
\hline 3. GaAs (middle) & 167.2 & off & off & 31.4 & 4.2 & 785.0 \\
\hline 4. GaAs-to-Ge LC & 167.2 & 261.1 & off & off & off & 785.0 \\
\hline 5. Ge (bottom) & 167.2 & 261.1 & off & off & off & 1064.0 \\
\hline
\end{tabular}


Yu Jeco-Espaldon et al.: Application of perovskite quantum dots in carrier redistribution...

Table 2 Modulated laser source specifications used for LBIC measurements.

\begin{tabular}{lccc}
\hline \hline Laser wavelength $(\mathrm{nm})$ & Spot size $(\mu \mathrm{m})$ & Measured power $(\mu \mathrm{W})$ & Power density $\left(\mathrm{mW} / \mathrm{cm}^{2}\right)$ \\
\hline 450 & 50 & 51.90 & 2643.25 \\
785 & 50 & 51.00 & 2597.41 \\
1064 & 100 & 53.40 & 679.91 \\
\hline \hline
\end{tabular}

light bias exciting GaAs, its LC current collection was measured. Then through direct laser excitation, the GaAs photocurrent collection maps were acquired by switching on continuous 440-, 970-, and 1550-nm LEDs (condition 3). With these LEDs, a 785-nm pulsed laser was activated to excite GaAs. As for the bottom cell, the Ge LC current collection maps were obtained by switching on continuous 440- and 660-nm LEDs simultaneously (condition 4). Then a 785-nm pulsed laser was also activated to excite GaAs. Since there was no light bias exciting Ge, its LC current collection was measured. Finally, by direct 1064-nm laser excitation, the Ge photocurrent collection maps were acquired by switching on continuous 440- and 660-nm LEDs (condition 5). The specifications of the modulated lasers used in LBIC mapping are summarized in Table 2.

The lasers have a duty cycle of $50 \%$, a switching frequency of $2000 \mathrm{~Hz}$, and a scanning frequency of $2 \mathrm{~Hz}$. For performance stability, the temperature of the lasers was kept at $20^{\circ} \mathrm{C}$.

\subsubsection{External quantum efficiency}

To determine the number of incident photons successfully converted into electrons, subcell EQE measurements were performed on the III-V based MJSC samples. First, an external voltage was applied across the 3JSC sample. Then the evaluated subcell was made current-limiting using continuous LED settings as listed in Table 1. Next, continuous light from a white lamp source with a global air mass 1.5 (AM 1.5G) filter was passed through a monochromator and a chopper to produce an optical AC signal with different wavelengths. The generated AC signal response was then measured using a lock-in amplifier. Finally, the EQE signal generated was recorded in a desktop computer connected to the setup components.

\subsubsection{Current-voltage (J-V) characteristics measurement}

The DC $J-V$ characteristics measurements were obtained under global air mass 1.5 (AM 1.5G) sunlight conditions from InGaP/GaAs/Ge 3JSC samples before and after PQD-COC film application. For these measurements, an AM 1.5G filtered white lamp was used and precalibrated using a $0.1-\mathrm{cm}^{2}$ crystalline silicon photodiode detector with known current production at 1 sun.

\subsection{Data Analysis}

\subsubsection{Integrated current density at $A M 1.5 G$}

The reference spectrum for the EQE measurements used was the AM 1.5G standard. From the subcell $\mathrm{EQE}$ measurements, the equivalent AM $1.5 \mathrm{G}$ current density at an applied terminal voltage $V, J_{\mathrm{AM} 1.5 \mathrm{G}}(V)$, was calculated by integrating the solar irradiance within the absorption range of a certain subcell. This is given as

$$
J_{\mathrm{AM} 1.5 \mathrm{G}}(V)=\frac{q}{h c} \int_{\lambda_{i-1, \mathrm{LL}}}^{\lambda_{i-1, \mathrm{UL}}} \lambda \times \mathrm{EQE}(\lambda, V) \times I_{\mathrm{AM} 1.5 \mathrm{G}}(\lambda) \mathrm{d} \lambda .
$$

Here $\operatorname{EQE}(\lambda, V)$ is the subcell $\mathrm{EQE}$ response to incident wavelength $\lambda$ at $V, I_{\mathrm{AM} 1.5 \mathrm{G}}(\lambda)$ is the reference AM 1.5G solar spectrum irradiance at each wavelength based on the ASTM G173-03 standard ${ }^{52} \lambda_{i-1, \mathrm{UL}}$ and $\lambda_{i-1, \mathrm{LL}}$ are the upper and the lower limits of the subcell absorption range, 
respectively, and the remaining variables are commonly known constants. The absorption ranges of the $\mathrm{InGaP} / \mathrm{GaAs} / \mathrm{Ge} 3 \mathrm{JSC}$ subcells were determined from the EQE measurements obtained.

\subsubsection{Standard deviation of the current collection}

From the LBIC measurements, the standard deviation of the current collection $\sigma_{x}$ given as

$$
\sigma_{x}=\sqrt{\frac{1}{N-1} \sum_{l=1}^{N}\left|J_{l}-\bar{J}\right|^{2}}
$$

was calculated to quantify the spatial uniformity of current production by inducing the LC effect $^{12,15}$ or by direct single-wavelength excitation on the current-limiting cell of the 3JSC samples before and after PQD film deposition. In this equation, the subscript $x$ refers to the direct subcell ( $x$ : DS) or to the LC effect ( $x$ : LC) excitation, $N$ is the total number of points in an LBIC map, $J_{l}$ is the current collected at a spot $l$, and $\bar{J}$ is the average subcell current obtained at all points on the map. Better current distribution uniformity is indicated by a lower value of $\sigma_{x}$.

\subsubsection{Percent differences}

To compare the samples before and after PQD-COC dip coating of 3JSCs, the percent difference of a parameter $Y, \% \Delta Y_{x}$, was calculated. Here $Y$ can be the average current production $J_{x, \text { ave }}$ or the standard deviations of the current collection $\sigma_{x}$ described in Eq. (2). $\% \Delta Y_{x}$ was calculated using the following relation:

$$
\% \Delta Y_{x}=\frac{Y_{x(\text { after })}-Y_{x(\text { before })}}{Y_{x(\text { before })}} \times 100 \%
$$

This was obtained to quantify the change in $Y$ before $\left[Y_{x \text { (before) }}\right]$ and after PQD-COC film deposition $\left[Y_{x(\text { after })}\right]$ on the MJSC front surface. The following results indicate performance improvement after deposition: a positive $\% \Delta J_{x, \text { ave }}$ denotes an increase in the current collection, whereas a negative $\% \Delta \sigma_{x}$ is interpreted as current homogeneity improvement.

\section{Results and Discussion}

\subsection{Preliminary PQD-COC Deposition on a III-V Substrate}

Before application on full III-V MJSC devices, PQD-COC was first deposited on semi-insulated, undoped GaAs substrates. From the single-layer samples, the following were obtained: (1) the PL spectrum, from which the peak emission wavelength was acquired, (2) the qualitative PL under 365-nm UV light to augment the PL spectroscopy results, (3) the surface roughness, and (4) the thickness of PQD-COC films.

The PL spectrum of the $\mathrm{CsPb}_{2.5} \mathrm{Br}_{0.5}$ PQD without and with $\mathrm{COC}$ are shown in Figs. 7(a) and 7(b) (Appendix B), respectively. As shown in these images, the peak emission wavelength of the PQD on GaAs is about $680 \mathrm{~nm}$. In a span of 2 months, the PQD-COC on the GaAs sample exhibited less $\mathrm{PL}$ intensity degradation. This suggests that the COC preserved the PL properties of the $\mathrm{CsPbI}_{2.5} \mathrm{Br}_{0.5}$ PQDs under ambient air conditions. Moreover, the UV PL from the PQDCOC film on GaAs was observed to be more emissive than the sample without COC. The PQD films without (left) and with COC (right) under white room light and under 365-nm UV PL are shown in Figs. 9(a) and 9(b) (Appendix B), respectively.

The surface roughness of the $\mathrm{CsPb}_{2.5} \mathrm{Br}_{0.5} \mathrm{PQD}$ on GaAs without and with $\mathrm{COC}$ was obtained through atomic force microscopy (AFM) imaging, as shown in Fig. 10. The measurements of the surface roughness of the samples without and with COC were 9.79 and $1.33 \mathrm{~nm}$, respectively. Meanwhile, the average thicknesses of the PQD film on GaAs without and with 


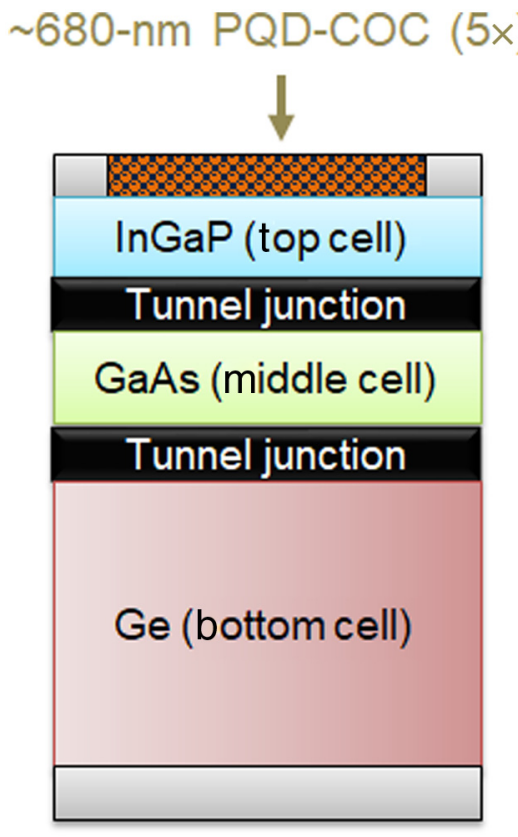

Fig. 2 InGaP/GaAs/Ge 3JSC with PQD-COC film on the front surface formed after 5 times of dip coating.

COC were found to be 1.021 and $1.089 \mu \mathrm{m}$, respectively. These values were obtained through the stylus profilometer measurements shown in Fig. 11 (Appendix B).

More details on the optical and surface characterization of PQD-COC on GaAs can be found in Appendix B.

\subsection{Current Collection and Homogeneity}

To determine the effect of adding PQD-COC on InGaP/GaAs/Ge 3JSCs, the LBIC maps were acquired from each subcell before and after dip coating 5 times, with GaAs being the limiting subcell in some cases. ${ }^{53,54}$ Figure 2 shows the simplified illustration of the $3 \mathrm{~J}$ sample with PQDCOC film on the front surface. The series of LBIC maps before and after PQD-COC DC are shown in Fig. 3. Also the $J_{x \text {,ave }}$ and $\sigma_{x}$ values together with their percent differences before and after PQD-COC DC are summarized in Tables 3 and 4, respectively.

Comparing the LBIC maps acquired through direct InGaP excitation before [Fig. 3(a)] and after [Fig. 3(b)] dip coating the 3J sample into the PQD-COC solution, the current collection in InGaP decreased after dip coating by $13.5 \%$, based on the $J_{\text {InGaP,ave }}$ values calculated from LBIC maps acquired. Furthermore, $\sigma_{\text {InGaP }}$ increased after dip coating by $11.4 \%$, indicating spatial current uniformity degradation. This suggests that the PQD-COC film was able to absorb some portion of the incident light before it reached the top cell.

As for the GaAs LC and direct 785-nm laser excitation, $12.3 \%$ and $7.5 \%$ increases in the current collection were observed after dip coating [Figs. 3(d) and 3(f)], as compared with the set of LBIC maps before dip coating [Figs. 3(c) and 3(e), respectively]. These results show that the PQD with COC was able to re-emit light toward GaAs. The PQD-COC deposition also improved the homogeneity of GaAs current collection by $19.2 \%$ [LC effect] and $21.0 \%$ [direct $785 \mathrm{~nm}$ ]. Meanwhile, $6.6 \%$ and $20.2 \%$ current collection increases and 5.54\% and 5.66\% current homogeneity improvements were observed from Ge LC and direct 1064-nm laser excitation, respectively. Because the light absorption in the GaAs middle cell was enhanced by the light emitted from the deposited PQD-COC film, the LC effect between GaAs and Ge subcells became stronger. This was reported in past literature that specifically tackled the LC effect between these subcells in $\mathrm{InGaP}_{\mathrm{GaAs}} / \mathrm{Ge}$ 3JSC devices. ${ }^{7-9,14,15}$

Collectively, the results from the LBIC measurements suggest that dip coating PQD on full III-V MJSCs is a potential solution for both current matching and homogenizing subcell current collection. 
Before $5 \times$ dip coating
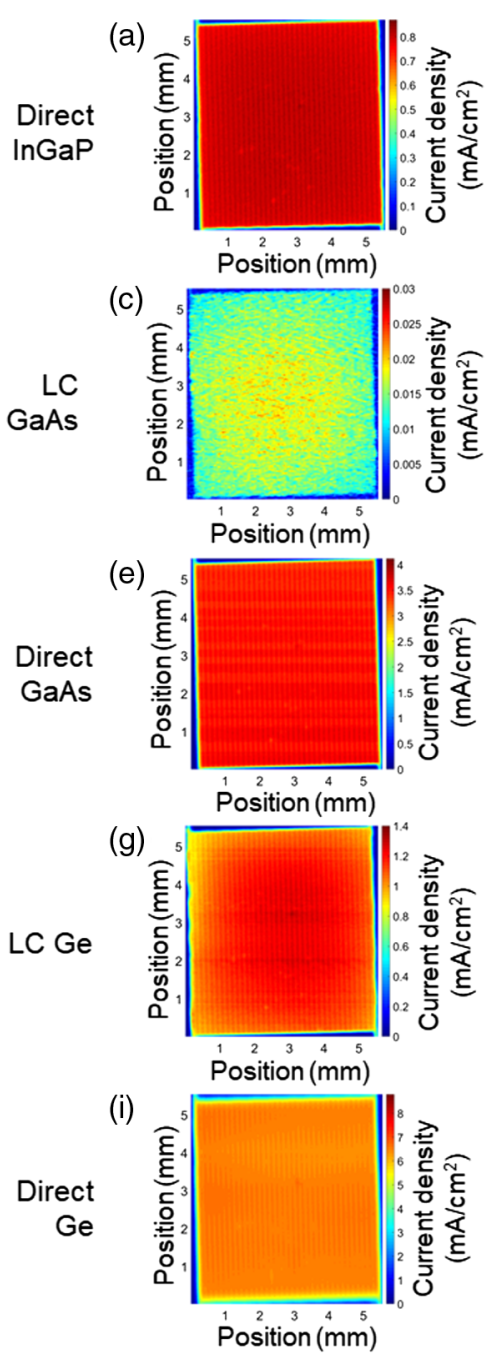

After $5 \times$ dip coating

(b)
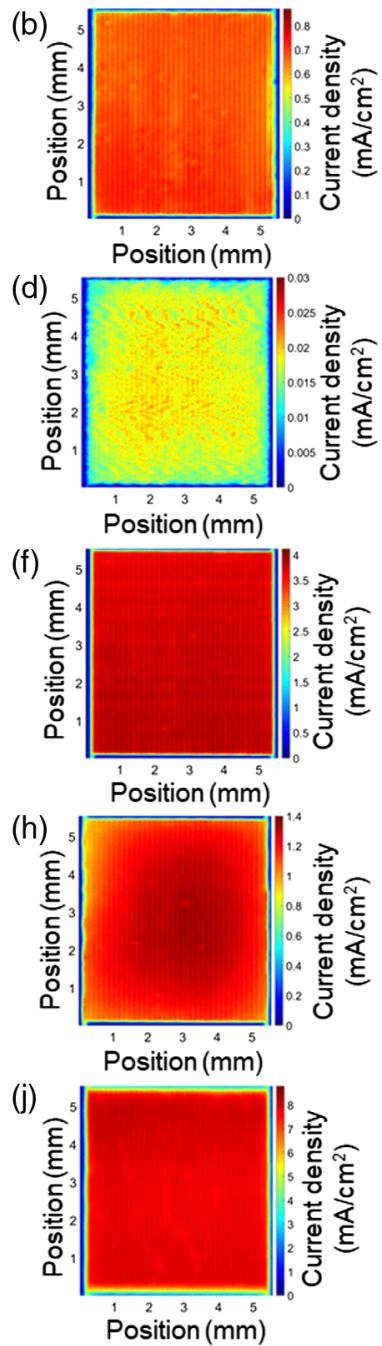

Fig. 3 LBIC measurements acquired before and after PQD-COC dip coating by (a), (b) direct InGaP excitation using a 450-nm laser; (c), (d) GaAs LC effect excitation using 450-nm laser; (e), (f) direct GaAs excitation using a 785-nm laser; (g), (h) Ge LC effect excitation using a 785-nm laser; and (i), (j) direct Ge excitation using a 1064-nm laser, respectively.

Table 3 Summary of the average current densities $J_{x, \text { ave }}$, before and after PQD-COC dip coating and their percent differences $\% \Delta J_{x, \text { ave }}$. Here positive $\% \Delta J_{x, \text { ave }}$ indicates current collection improvement.

\begin{tabular}{lccccc}
\hline \hline Condition & $J_{\text {InGaP,ave }}$ & $J_{\text {LCGaAs,ave }}$ & $J_{\text {GaAs,ave }}$ & $J_{\text {LCGe,ave }}$ & $J_{\text {Ge,ave }}$ \\
\hline Before dip coating $\left(\mu \mathrm{A} / \mathrm{cm}^{2}\right)$ & 788.6 & 15.4 & 3483.8 & 1138.4 & 6443.8 \\
After dip coating $\left(\mu \mathrm{A} / \mathrm{cm}^{2}\right)$ & 682.5 & 17.3 & 3745.0 & 1213.8 & 7748.5 \\
$\% \Delta J_{x, \text { ave }}(\%)$ & -13.5 & +12.3 & +7.5 & +6.6 & +20.2 \\
\hline \hline
\end{tabular}

\subsection{Subcell EQE Measurements}

The trend observed from the LBIC measurements shown in Fig. 3 was investigated further by comparing the subcell EQE measurements before and after PQD-COC dip coating. These measurements are shown in Fig. 4. Although the InGaP EQE decreased, some increase in the longer 
Table 4 Summary of the standard deviations of the current collection $\sigma$ before and after dip coating and their percent differences $\% \Delta \sigma$. Here negative $\% \Delta \sigma$ indicates current homogeneity improvement after PQD-COC dip coating.

\begin{tabular}{lccccc}
\hline \hline Condition & $\sigma_{\text {InGaP }}$ & $\sigma_{\text {LCGaAs }}$ & $\sigma_{\mathrm{GaAs}}$ & $\sigma_{\mathrm{LCGe}}$ & $\sigma_{\mathrm{Ge}}$ \\
\hline Before dip coating $\left(\mu \mathrm{A} / \mathrm{cm}^{2}\right)$ & 55.9 & 148.5 & 63.0 & 81.3 & 60.1 \\
After dip coating $\left(\mu \mathrm{A} / \mathrm{cm}^{2}\right)$ & 62.3 & 120.0 & 49.8 & 76.8 & 56.7 \\
$\% \Delta \sigma(\%)$ & +11.4 & -19.2 & -21.0 & -5.54 & -5.66 \\
\hline \hline
\end{tabular}

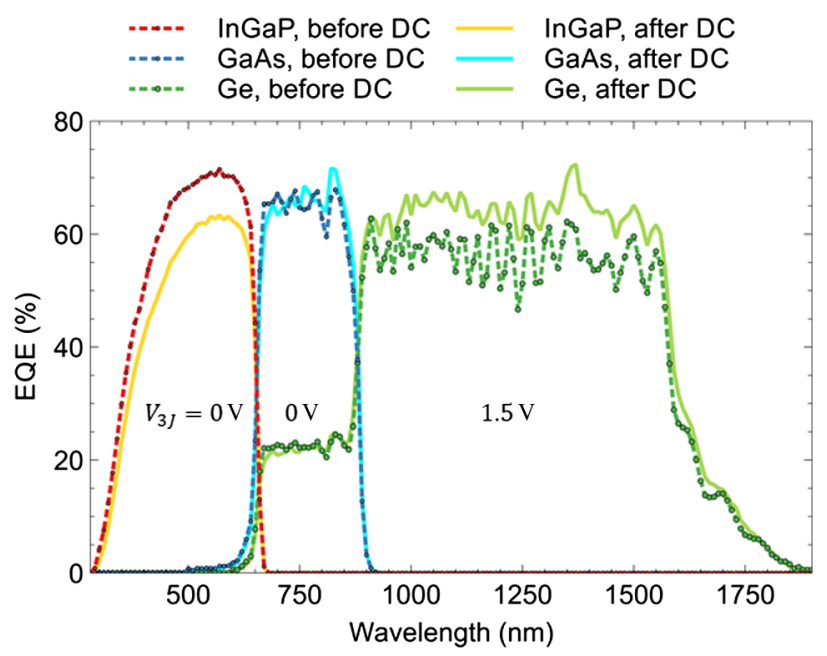

Fig. 4 Subcell EQE measurements from InGaP/GaAs/Ge 3JSC before (dotted lines) and after PQD-COC deposition (solid lines) by dip coating (DC) 5 times.

wavelength region of GaAs and an increase in Ge EQE were observed. The decrease of the InGaP EQE is inferred as the decrease in InGaP current density. On the other hand, the increases in both GaAs and Ge EQE measurements after PQD-COC dip coating indicate an increase in GaAs and Ge current densities. These were numerically confirmed by the calculations of $J_{\mathrm{AM} 1.5 \mathrm{G}, i}$ from the subcell EQE measurements using Eq. (1). These are summarized in Table 5. Before dip coating, the current-limiting cell was found to be the GaAs middle cell, having the lowest current density value of $10.3 \mathrm{~mA} / \mathrm{cm}^{2}$ among the subcells. After dip coating the $\mathrm{InGaP} /$ $\mathrm{GaAs} / \mathrm{Ge} 3 \mathrm{JSC}$ into the 680-nm PQD-COC solution, EQE measurement and $J_{\mathrm{AM} 1.5 \mathrm{G}, i}$ calculations revealed that photon re-emission from the PQD-COC film toward the middle cell occurred. These results then confirm that controlling current matching among subcells is possible through PQD-COC film deposition on full III-V MJSCs. On the other hand, the EQE increase in the Ge bottom cell further suggests that the increased absorption in the GaAs middle cell has led to a stronger LC effect between GaAs and Ge subcells.

Table 5 Integrated current density $J_{\mathrm{AM} 1.5 \mathrm{G}, i}$ values calculated from the subcell EQE measurements.

\begin{tabular}{lcc}
\hline \hline Current density & Before dip coating & After dip coating \\
\hline$J(V)_{\text {InGaP }}\left(\mathrm{mA} / \mathrm{cm}^{2}\right)$ & 11.0 & 9.6 \\
$J(V)_{\mathrm{GaAs}}\left(\mathrm{mA} / \mathrm{cm}^{2}\right)$ & 10.3 & 10.4 \\
$J(V)_{\mathrm{Ge}}\left(\mathrm{mA} / \mathrm{cm}^{2}\right)$ & 17.4 & 19.0 \\
\hline \hline
\end{tabular}




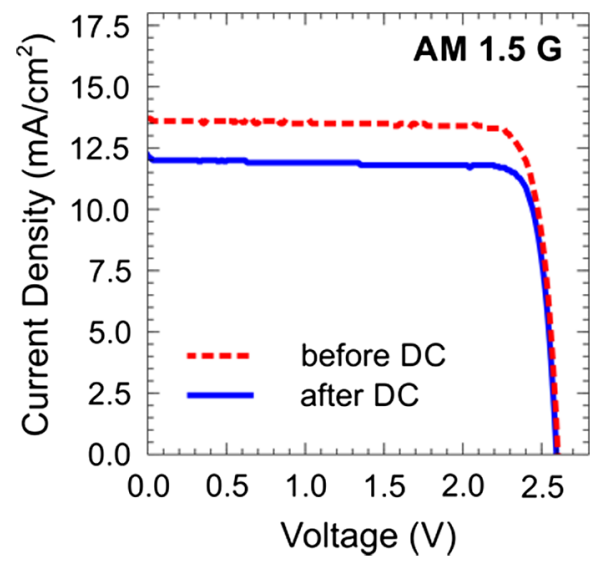

Fig. 5 One sun, AM 1.5G light $J-V$ characteristic curves before (dotted lines) and after PQD-COC deposition (solid lines) by dip coating (DC) 5 times.

\subsection{Impact on the 1-sun J-V Characteristics}

To determine the impact of adding $\mathrm{CsPbX}_{3}$ PQDs with the moisture encapsulant on the net performance of the MJSCs, $J-V$ characteristics were obtained across the sample terminals before and after PQD-COC deposition on full InGaP/GaAs/Ge 3JSC devices at 1 sun. The $J-V$ characteristics measurement at AM 1.5G, 1 sun condition, showed a decrease [Fig. 5], confirming further that InGaP became the current limiting cell. This decrease, which corresponds to its EQE and $J_{\mathrm{AM} 1.5 \mathrm{G}, \text { InGaP }}$ decreases, implies that the thickness of the PQD film is not yet optimum. Hence, optimizing the PQD-COC film thickness to be applied on current-mismatched MJSC devices could be a step closer to improved MJSC conversion efficiency in the bigger picture.

\subsection{PQD-COC Deposition as an Additional Step in III-V MJSC Device Fabrication}

Reflectance measurements of PQD on GaAs samples with and without COC solution added to the $\mathrm{CsPbX}_{3}$ PQD solution were obtained. This was done to determine if the refractive indices $n$ of the films are larger or smaller than those of the III-V materials typically used as solar cell absorbers. Details on how to qualitatively determine $n$ can be found in Appendix C.

Figure 6 shows the reflectivity spectra of a GaAs substrate dipped 5 times on a PQD-COC solution, together with those of HCl-treated, bare GaAs substrate and those from the published

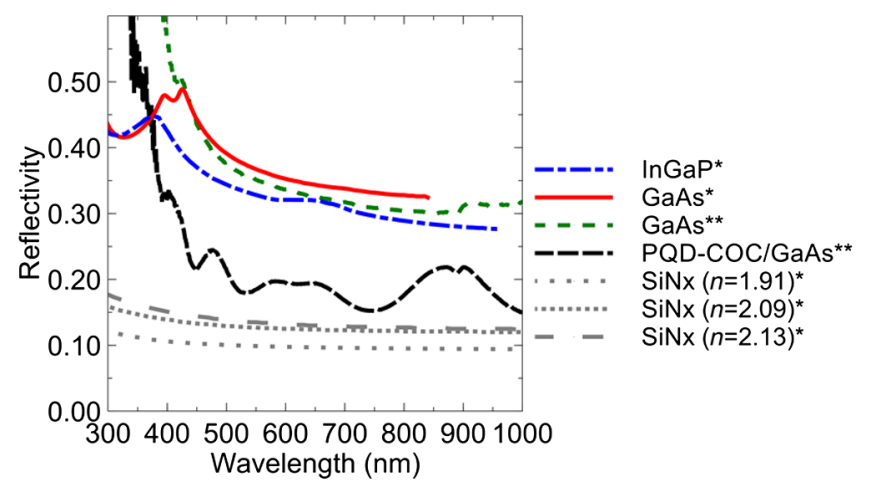

Fig. 6 Reflectivity spectra derived from GaAs substrates dip coated 5 times on PQD solutions with and without $\mathrm{COC}$ added. These are plotted together with the reflectivity of InGaP, ${ }^{55} \mathrm{GaAs},{ }^{56}$ and $\mathrm{SiN}_{x},{ }^{57}$ derived from optical constants, $n$ and $k$. Plots with * on their labels were obtained from previous literature, while plots with ${ }^{* \star}$ were acquired experimentally. 
spectrally resolved $n$ and extinction coefficient $k$ values of $\operatorname{InGaP}^{55}$ and GaAs. ${ }^{56}$ The spectra were calculated using Eq. (6). The PQD-COC film had a larger $R$, and therefore a larger $n$, than silicon nitride $\left(\mathrm{SiN}_{x}\right)$. $\mathrm{SiN}_{x}$ is typically used as an antireflection coating (ARC) for solar cells, with $n$ value being less than those of the III-V materials. Considering light refraction, the active layers of an MJSC should be stacked from the lowest refractive index to the highest, following the direction of the incident light. Hence, it can be inferred from Fig. 6 that the PQD-COC film can be deposited after growing the III-V stack but before the deposition of an ARC such as $\mathrm{SiN}_{x}{ }^{57}$

Alternately, if the MJSC is already fabricated, the limiting subcell current should be determined first. Then an optimum PQD-COC film thickness should be fabricated, as recommended earlier.

\section{Conclusion}

A pathway to possibly homogenize and increase current collection in a limiting cell of a III-V MJSC device is through the application of a PQD-amorphous thermoplastic film. The PQDCOC on a full III-V MJSC device successfully demonstrated current redistribution from the top cell and improved current homogeneity in the lower subcells-either by direct light re-emission from the PQD-COC layer or by consequently enhancing the LC effect between adjacent lower bandgap subcells. Thus for enhanced MJSC current matching, the use of a photoassistive layer like $\mathrm{PQD}$, encapsulated with $\mathrm{COC}$ or other hydrophobic, amorphous thermoplastic films is recommended.

\section{Appendix A: Detailed $\mathrm{CsPbl}_{2.5} \mathrm{Br}_{0.5} \mathrm{PQD}$ Synthesis Steps}

\subsection{Part 1: 100-mL Cs-oleate Precursor Flask}

1. Place a magnetic stirrer inside the precursor flask (PF).

2. Set the stirring plate rpm to 150 or higher. There is no need to set an exact rpm.

3. Add $0.25 \mathrm{~g}$ cesium carbonate $\left(\mathrm{CsCO}_{3}\right)$, and then pour $1.0-\mathrm{mL}$ oleic acid $(\mathrm{OA})$ and $25-\mathrm{mL}$ 1-octadecene (ODE) into the PF.

4. Stir and degas the $\mathrm{PF}$ under vacuum for $1 \mathrm{~h}$ at $120^{\circ} \mathrm{C}$.

5. Purge the PF with argon (Ar) gas.

6. Heat the $\mathrm{PF}$ to $150^{\circ} \mathrm{C}$ until the precursor solution becomes clear.

7. Cool down and keep the PF contents in ambient Ar gas until it is needed for QD synthesis.

\subsection{Part 2: $\mathrm{Cs}_{\mathrm{Pbl}} \mathrm{Br}_{0.5} \mathrm{PQD}$ Synthesis}

1. Add a magnetic stirrer inside another empty flask. This will be designated as the RF.

2. Set its stirring plate rpm to 150 or higher. There is no need to set an exact rpm.

3. Add $0.5 \mathrm{mM}$ of $\mathrm{PbI}_{2}$ and $0.1 \mathrm{mM}$ of $\mathrm{PbBr}_{2}$ into the RF.

4. Pour 8-mL 1-ODE into the RF.

5. Stir and degas the RF under vacuum for $1 \mathrm{~h}$ at $120^{\circ} \mathrm{C}$.

6. Purge the RF with Ar gas.

7. Inject $1.0-\mathrm{mL} \mathrm{OA}$ and $1.0-\mathrm{mL}$ oleylamine into the RF.

8. Stir and degas the $\mathrm{RF}$ under vacuum until the $\mathrm{PbX}_{3}$ solutes are completely dissolved. When solutes are fully dissolved, the solution becomes transparent, that is, it changes its color from yellow to transparent brown-like.

9. Purge the RF with Ar gas while heating it to the reaction (synthesis) temperature of $170^{\circ} \mathrm{C}$.

10. Inject $2.0 \mathrm{~mL}$ of Cs-oleate from the $\mathrm{PF}$, preheated to $80^{\circ} \mathrm{C}$, into the $\mathrm{RF}$.

11. Cool the RF in the ice water bath while hand stirring it for about $5 \mathrm{~s}$. 


\subsection{Part 3: Synthesized CsPbl $2.5 \mathrm{Br}_{0.5} P Q D$ Wash}

1. Pour $30 \mathrm{~mL}$ of ethyl acetate into the RF.

2. Transfer the PQD solution from the RF to a new, empty centrifuge tube.

3. Get the weight of the centrifuge tube containing the PQD solution.

4. Fill another centrifuge tube with $\mathrm{H}_{2} \mathrm{O}$, with the same weight as that of the PQD tube for centrifuge machine balancing.

5. Place the centrifuge tubes on the centrifuge machine slots opposite each other.

6. Run the centrifuge machine at $8000 \mathrm{rpm}$ for $5 \mathrm{~min}$.

7. Discard the liquid from the PQD tube, leaving behind the accumulated PQDs.

8. Pour 3-mL hexane and 3-mL methyl acetate into the PQD tube with accumulated dots (anhydrous, open bottle in a dry room).

9. Subject the PQD tube to ultrasonic bath for about $20 \mathrm{~s}$ until nothing is seen settling at the bottom of the tube.

10. Repeat steps 3 to 5 .

11. Run the centrifuge machine at $8000 \mathrm{rpm}$ for $2 \mathrm{~min}$.

12. Discard the liquid from the PQD tube, leaving behind the accumulated PQDs.

\subsection{Part 4: Setting the PQD Solution Concentration}

1. Measure the mass of a disposable glass bottle.

2. Transfer the centrifuged PQD solution into the empty glass bottle with known mass.

3. Dry the PQD solution with Ar gas until its solvent is fully evaporated.

4. Measure the glass bottle again, but this time with the dried $\mathrm{CsPbI}_{2.5} \mathrm{Br}_{0.5} \mathrm{PQD}$.

5. Calculate the required solvent $\left(\mathrm{C}_{6} \mathrm{H}_{14}\right)$ volume according to the desired PQD solution concentration.

6. Add the required solvent volume into the bottle with dried $\mathrm{CsPbI}_{2.5} \mathrm{Br}_{0.5}$ PQD.

7. Shake well to disperse the PQDs and prepare the solution for dip coating.

\section{Appendix B: Profiling of PQD-COC on GaAs Substrate}

\subsection{Photoluminescence Spectroscopy of PQD-COC on GaAs Substrate}

PL spectroscopy measurements were obtained for $\mathrm{CsPbI}_{2.5} \mathrm{Br}_{0.5}$ PQDs on GaAs substrates between 500 and $950 \mathrm{~nm}$. In the PL measurement setup, a continuous 532-nm laser was used to excite the PQDs on GaAs samples, having it pass through an IR-absorbing filter, a transmission filter, and a series of mirrors and a beam splitter. The output power of the laser before it passes through the mentioned optical elements ranges from 60 to $70 \mathrm{~mW}$. The spot size of the 532-nm laser is about $100 \mu \mathrm{m}$. The transmissivity of the filter used was $10 \%$ and the exposure time of the charge-coupled device camera detector was fixed at $20 \mathrm{~ms}$. These settings were used such that PL intensities of the samples would not saturate the detector. Also the grating and the slit width of the photodetector were fixed at 150 gratings $/ 500 \mathrm{~nm}$ and $50 \mu \mathrm{m}$, respectively. To compare the PL emission spectra appropriately, the samples were mounted alongside each other such that the mount was only moved along one axis. Then each sample was excited approximately at its center.

PL emission spectra were obtained at different times after dip coating GaAs substrates five times into $\mathrm{CsPbI}_{2.5} \mathrm{Br}_{0.5}$ PQD solutions without [Fig. 7(a)] and with COC [Fig. 7(b)], simultaneously. It was observed that the PL emission intensities were larger in samples with no COC than those from substrates with $\mathrm{COC}$ within $48 \mathrm{~h}$ after dip coating. In this instance, the samples had experienced an average of $60 \%$ humidity. The larger PL from samples without COC may be attributed to the lower volatility of the PQD-COC solution than the PQD solution without COC, that is, the latter's solvent evaporated faster than that of the PQD-COC. As a result, the PQD solution without COC may have had a larger effective concentration than the PQD-COC solution, which then could have allowed a larger number of PQDs to be deposited on the GaAs substrates. Hence, a higher PL was observed within the spot area of the 532-nm excitation laser 

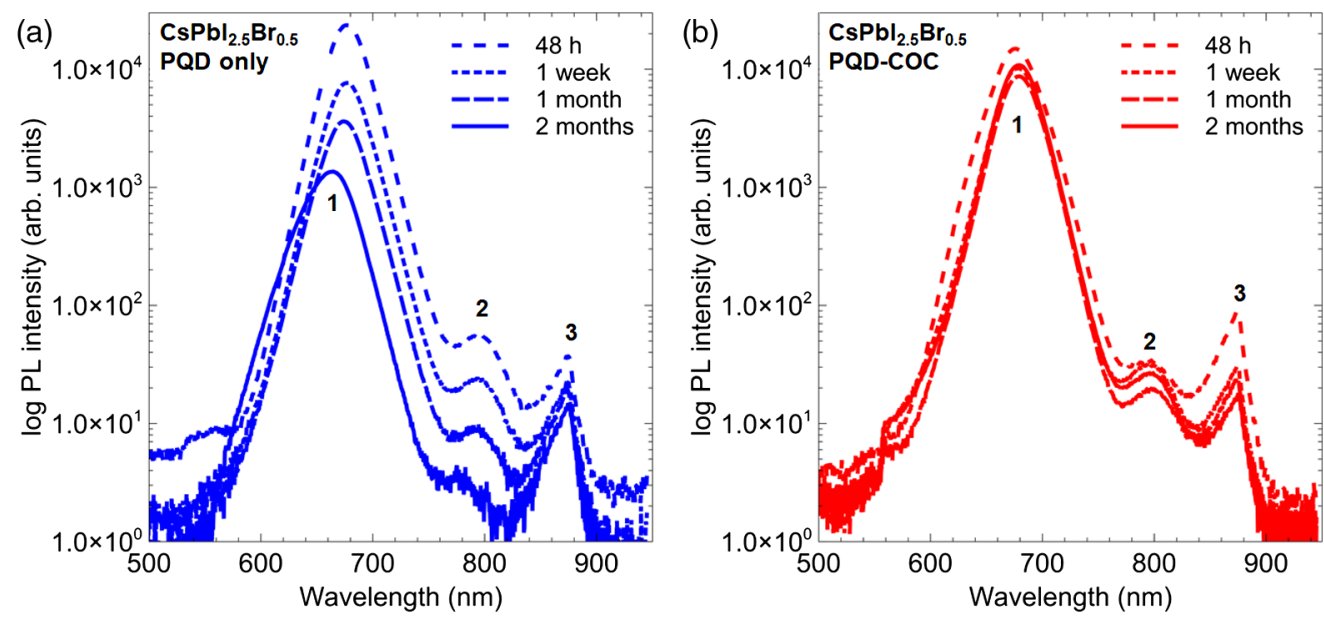

Fig. $7 \mathrm{PL}$ emission spectra at 532-nm laser excitation upon (a) $\mathrm{CsPbl}_{2.5} \mathrm{Br}_{0.5} \mathrm{PQD}$ on $\mathrm{GaAs}$ and (b) $\mathrm{CsPbl}_{2.5} \mathrm{Br}_{0.5} \mathrm{PQD}-\mathrm{COC}$ on GaAs after dip coating 5 times and being kept under average (ambient) humidity of $56 \%$ to $60 \%$ for different lengths of time. Emission peaks labeled with numbers 1, 2, and 3 correspond to those from PQDs having about 10-nm diameter, 20-nm diameter, and from GaAs substrates, respectively.

of the PQD on the GaAs sample. However, after a week to 2 months of experiencing average humidity between $56 \%$ and $57 \%$, the PQD-COC on the GaAs sample exhibited less variation in PL emission, whereas the PQD on the GaAs sample showed a decrease in PL emission over time. From these results, it may be inferred that the COC was able to protect the PQDs from ambient moisture, and without COC, the PQD film oxidized overtime under ambient humidity. Hence, COC, a hydrophobic material, can act as a moisture barrier that may preserve the desired optical properties of the $\mathrm{CsPbX}_{3}$ PQDs.

The addition of the COC solution to the PQD solution before substrate dip coating did not alter the peak emission wavelength $\lambda_{\text {peak, } 1}$, which was around $680 \mathrm{~nm}$ [Table 6]; hence, the COC did not cause regressive effects on the $\lambda_{\text {peak }}$ of the PQDs. On the other hand, a blue shift of about $10 \mathrm{~nm}$ was observed from $\lambda_{\text {peak, } 1}$ of the PQD sample without COC after 2 months. This could be due to the oxidation of the film, leading to film volume reduction as observed in quantum dots intended for live cells. ${ }^{58}$ The expected PQD sizes $D_{\mathrm{PQD}}$ were calculated using an empirical formula $^{59}$

$$
D_{\mathrm{PQD}}=0.344 \exp \left(\frac{\lambda_{\text {peak }}-252.7}{129.3}\right)
$$

where $\lambda_{\text {peak }}$ is the $\mathrm{CsPbX}_{3}$ PQD peak emission wavelength obtained from PL spectroscopy. Based on the measured $\lambda_{\text {peak, } 1}$ values corresponding to peak 1 in Fig. 7 as listed in Table 6,

Table 6 Summary of peak PL intensities $\lambda_{\text {peak }}$ obtained from $\mathrm{CsPb}_{2.5} \mathrm{Br}_{0.5} \mathrm{PQD}$ on GaAs samples without and with $\mathrm{COC}$.

\begin{tabular}{|c|c|c|c|c|c|c|c|}
\hline \multirow[b]{2}{*}{ Period } & \multirow{2}{*}{$\begin{array}{c}\text { Average } \\
\text { humidity (\%) }\end{array}$} & \multicolumn{2}{|c|}{$\begin{array}{c}\text { Primary PQD peak } \\
\text { PL wavelength, } \\
\lambda_{\text {peak, } 1}(\mathrm{~nm})\end{array}$} & \multicolumn{2}{|c|}{$\begin{array}{c}\text { Secondary PQD } \\
\text { peak PL wavelength, } \\
\lambda_{\text {peak } k, 2}(\mathrm{~nm})\end{array}$} & \multicolumn{2}{|c|}{$\begin{array}{c}\text { GaAs peak PL } \\
\text { wavelength, } \lambda_{\text {peak }, 3} \\
(\mathrm{~nm})\end{array}$} \\
\hline & & no COC & w/COC & no COC & $\mathrm{w} / \mathrm{COC}$ & no COC & $\mathrm{w} / \mathrm{COC}$ \\
\hline $48 \mathrm{~h}$ & 60 & 676 & 676 & 760 & 761 & 874 & 874 \\
\hline 1 week & 57 & 677 & 679 & 795 & 796 & 874 & 873 \\
\hline 1 month & 56 & 673 & 680 & 790 & 798 & 874 & 874 \\
\hline 2 months & 57 & 664 & 680 & 775 & 795 & 875 & 875 \\
\hline
\end{tabular}


Table 7 Summary of estimated PQD diameters $D_{\mathrm{PQD}}$ based on the measured $\lambda_{\text {peak }}$ of $\mathrm{CsPbl}_{2.5} \mathrm{Br}_{0.5} \mathrm{PQD}$ on GaAs samples without and with COC.

\begin{tabular}{lcccccc}
\hline \hline & & \multicolumn{2}{c}{$D_{\mathrm{PQD}, 1}(\mathrm{~nm})$} & & \multicolumn{2}{c}{$D_{\mathrm{PQD}, 2}(\mathrm{~nm})$} \\
Period & $\begin{array}{c}\text { Average } \\
\text { humidity }(\%)\end{array}$ & no COC & w/COC & & no COC & w/COC \\
\hline $48 \mathrm{~h}$ & 60 & 9.1 & 9.1 & 17.5 & 17.5 \\
1 week & 57 & 9.1 & 9.3 & & 22.7 & 22.9 \\
1 month & 56 & 8.9 & 9.3 & & 21.9 & 23.3 \\
2 months & 57 & 8.3 & 9.3 & & 19.6 & 22.8 \\
\hline \hline
\end{tabular}

the expected $D_{\mathrm{PQD}, 1}$ values were calculated using Eq. (4). The results of the calculations are presented in Table 7.

Although it was not expected, a weak secondary peak emission, $\lambda_{\text {peak,2, }}$, appeared between 760 and $840 \mathrm{~nm}$ wavelengths in all logarithmic PL spectra plots measured from both samples, as shown in Fig. 7. This could be attributed to the PQDs that formed aggregates during dip coating, making the effective dot size in some areas of the substrate be about $20 \mathrm{~nm}$. The sizes of the PQD aggregates based on the measured $\lambda_{\text {peak,2 }}\left(D_{\mathrm{PQD}, 2}\right)$ are summarized in Table 7 . These were confirmed by scanning electron microscopy (SEM) imaging of $\mathrm{CsPb}_{2.5} \mathrm{Br}_{0.5} \mathrm{PQDs}$ on the GaAs substrate shown in Fig. 8. During the counting, the SEM image was partitioned into $4 \times 6$ parts or a total of $400 \times 600 \mathrm{~nm}^{2}$. A box plot of the number of dots per area was provided [Fig. 8(c)]. Here the dots were clustered as either having a diameter of $\sim 10$ or $20 \mathrm{~nm}$.

PL peak emission from the GaAs regime of all samples $\lambda_{\text {peak }, 3}$ was observed between 800 and $900 \mathrm{~nm}$. This was weak compared with the $\lambda_{\text {peak }, 1}$ because there was no carrier confinement structure $^{60}$ or a passivation layer ${ }^{61-70}$ that may assist absorption or emission grown on the GaAs

(a)

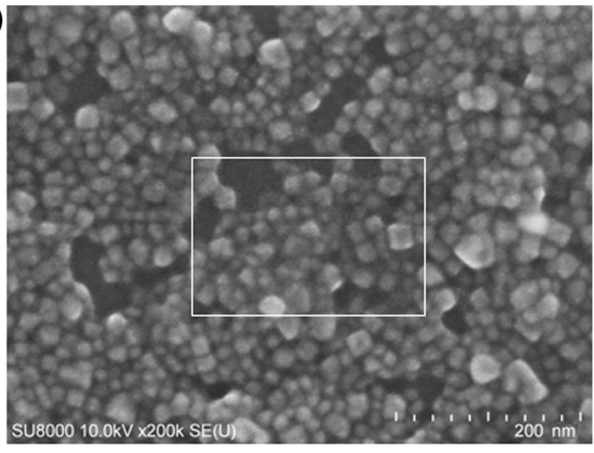

(b)

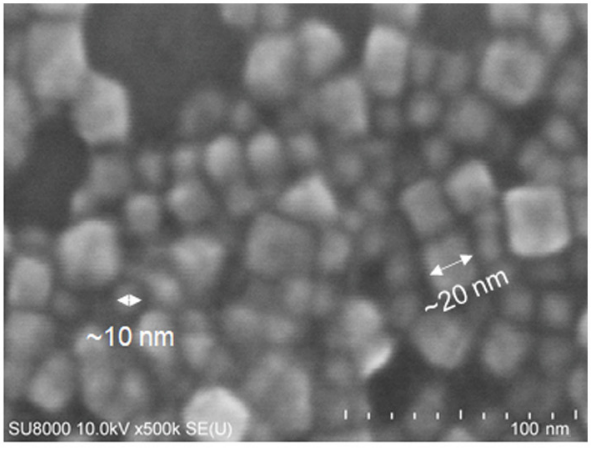

(c) $\varepsilon$

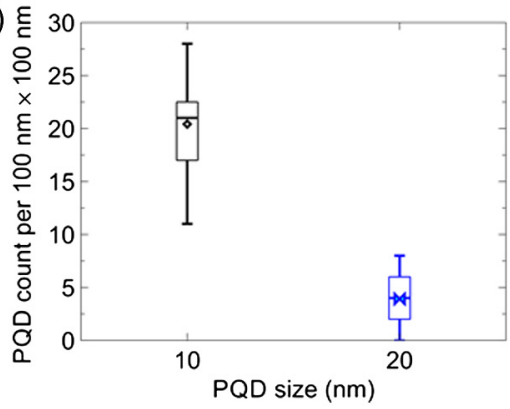

Fig. 8 SEM images of $\mathrm{CsPbl}_{2.5} \mathrm{Br}_{0.5}$ PQD film on undoped, semi-insulated, GaAs substrate at (a) $\times 200 \mathrm{k}$ magnification and (b) $\times 500 \mathrm{k}$ magnification of the region enclosed in the white box in (a). The sample was withdrawn at a speed of $5 \mathrm{~mm} / \mathrm{s}$ from a tank containing a $\mathrm{CsPbl}_{2.5} \mathrm{Br}_{0.5} \mathrm{PQD}$ solution for 5 dip cycles. (c) Box plot of the number of PQDs having different sizes for every $100 \times 100 \mathrm{~nm}^{2}$ area observed. 
(a)

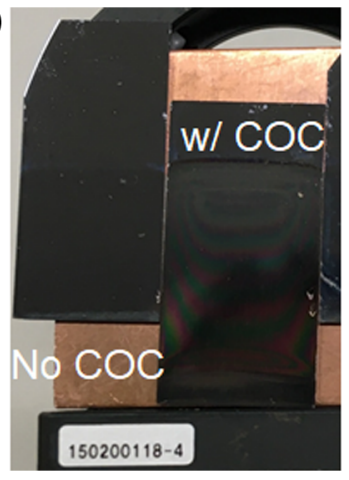

(b)

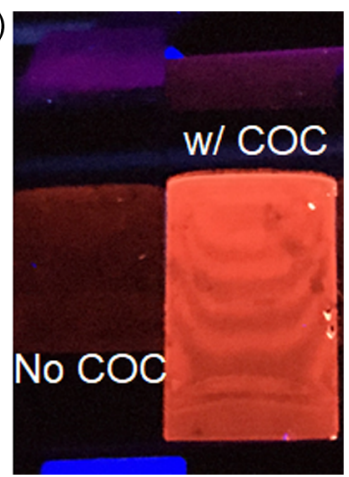

Fig. 9 (a) $\mathrm{CsPbl}_{2.5} \mathrm{Br}_{0.5} \mathrm{PQD} / \mathrm{GaAs}$ and $\mathrm{CsPbl}_{2.5} \mathrm{Br}_{0.5} \mathrm{PQD}-\mathrm{COC} / \mathrm{GaAs}$ samples under white room light. (b) $\mathrm{PL}$ emission of $\mathrm{CsPbl}_{2.5} \mathrm{Br}_{0.5} \mathrm{PQD} / \mathrm{GaAs}$ and $\mathrm{CsPbl}_{2.5} \mathrm{Br}_{0.5} \mathrm{PQD}-\mathrm{COC} / \mathrm{GaAs}$ samples under a 365-nm UV lamp, within $48 \mathrm{~h}$ after deposition.

substrate. Hence, improving the interface between the PQD film and the GaAs substrate ${ }^{71}$ may increase the PL intensity in the latter.

To further investigate the PL observations, the samples were subjected to 365-nm UV irradiation in a dark room within $48 \mathrm{~h}$ after DC. Figures 9(a) and 9(b) show the PQD films without and with COC under white room light and under a 365-nm UV lamp, respectively. Upon exposing the samples under the 365-nm UV lamp at room temperature with $49 \%$ humidity on the day of dip coating (December 6, 2019), the PL emission from the PQD-COC films were observed to be much stronger as compared with samples having PQD films only. Comparing with the PL spectra obtained through 532-nm laser excitation within $48 \mathrm{~h}$ after dip coating, the UV-PL images suggest that the PL emission strength of PQD films have an excitation wavelength dependence. Nevertheless, the UV-PL images confirm the effectiveness of COC in protecting the optical performance of $\mathrm{CsPbI}_{2.5} \mathrm{Br}_{0.5}$ PQDs under an environment with high-humidity and high-light energy exposure.

\subsection{Surface Morphology}

The surface morphology of $\mathrm{CsPbI}_{2.5} \mathrm{Br}_{0.5} \mathrm{PQDs}$ deposited on GaAs substrates was evaluated through AFM imaging. During imaging, a $3 \mu \mathrm{m} \times 3 \mu \mathrm{m}$ surface approximately within the center of the sample was observed. From these measurements, the root-mean-square values of the PQD film surface roughness $S_{q}$ were obtained. This parameter was interpreted depending on the expected PQD nanocrystal size $D_{\mathrm{PQD}}$, which can be predicted using Eq. (4). If the $S_{q}$ value acquired was less than or equal to $D_{\mathrm{PQD}}$, the deposited film was considered optically smooth. Also a lower $S_{q}$ value indicates better PQD deposition uniformity.

To compare the surface morphologies of the samples with and without the COC solution added to the PQD solution, AFM images were obtained from PQD films without and with COC on GaAs. These images are shown in Figs. 10(a) and 10(b), respectively. The one with COC garnered a lower $S_{q}$ of $1.33 \mathrm{~nm}$; hence, it is optically smoother than the one without COC $\left(S_{q}=9.79 \mathrm{~nm}\right)$. In this aspect, PQD films with COC are more desirable than those without COC.

\subsection{Film Thickness Measurement}

The thicknesses of $\mathrm{CsPbI}_{2.5} \mathrm{Br}_{0.5} \mathrm{PQD}$ films on GaAs substrates were measured using a stylus profilometer. These were measured at a scanning resolution of $0.167 \mu \mathrm{m}$ using a $12.5-\mu \mathrm{m}$-radius stylus set to 2-mg scanning force. The average thicknesses of the PQD film on GaAs without and with COC were 1.021 and $1.089 \mu \mathrm{m}$, respectively. The average values were acquired from the height profile shown in Fig. 11 after a leveling correction was applied. These measurements were obtained 3 days after dip coating. 
(a)

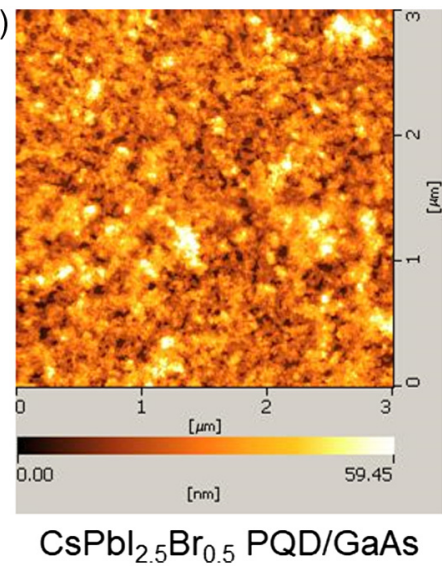

(b)

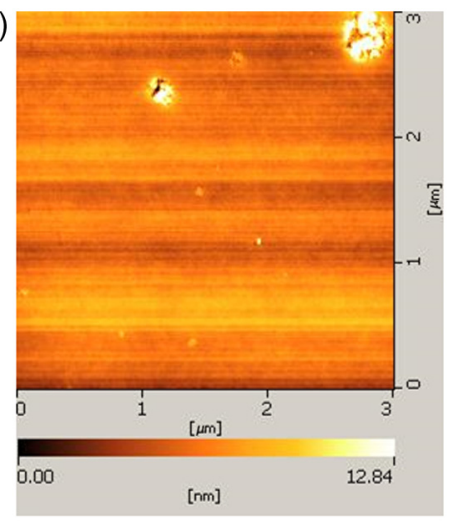

$\mathrm{CsPbl}_{2.5} \mathrm{Br}_{0.5} \mathrm{PQD}-\mathrm{COC} / \mathrm{GaAs}$

Fig. 10 AFM images of (a) $\mathrm{CsPbl}_{2.5} \mathrm{Br}_{0.5} \mathrm{PQD}$ on GaAs and (b) $\mathrm{CsPb}_{2.5} \mathrm{Br}_{0.5} \mathrm{PQD}-\mathrm{COC}$ on GaAs after dip coating 5 times and kept under an average (ambient) humidity of $56 \%$ to $60 \%$. These images were obtained within $48 \mathrm{~h}$ after 5 times of dip coating.

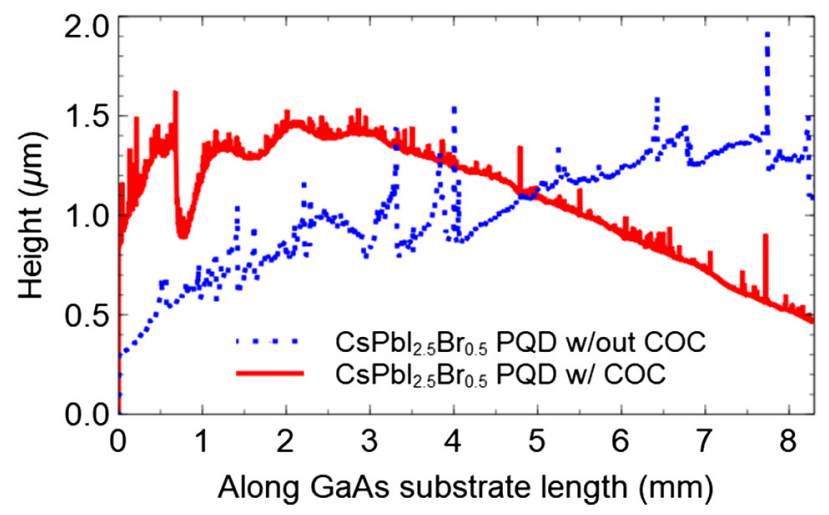

Fig. 11 Height profiles of $\mathrm{CsPbl}_{2.5} \mathrm{Br}_{0.5}$ PQD on GaAs (dotted line) and $\mathrm{CsPbl}_{2.5} \mathrm{Br}_{0.5}$ PQD-COC on GaAs (solid line) after DC 5 times and being kept under an average (ambient) humidity of $56 \%$ to $60 \%$ acquired through stylus profilometry. These profiles were obtained 3 days after DC.

\section{Appendix C: Qualitative Determination of Refractive Indices of Various III-V and PQD-COC Materials}

Reflectance measurements on $\mathrm{HCl}$-treated $\mathrm{GaAs}$ substrates with amorphous thermoplastic (COC) only, with $\mathrm{CsPb}_{2.5} \mathrm{Br}_{0.5}$ PQD film only, with $\mathrm{CsPbI}_{2.5} \mathrm{Br}_{0.5} \mathrm{PQD}-\mathrm{COC}$ film, and without any film deposited on them were obtained. This was done to qualitatively compare the refractive indices of each sample through normalized reflectance calculations $R$ with respect to the III-V materials with known values. With the results of the calculations, the appropriate stacking of PQDs together with III-V solar cell materials to form tandem or multijunction structures may be inferred. From the reflectance measurements, $R$ can be calculated from the following relation:

$$
R=\frac{\operatorname{Ref}_{\text {sample }}-\operatorname{Ref}_{\mathrm{bg}}}{\operatorname{Ref}_{\mathrm{Ag}}-\operatorname{Ref}_{\mathrm{bg}}}
$$

where $\operatorname{Ref}_{\mathrm{Ag}}$ is the measured reference silver mirror reflectance, $\operatorname{Ref}_{\mathrm{bg}}$ is the background reflectance, and Ref $_{\text {sample }}$ is the measured reflectance of the sample. From the published wavelengthresolved optical constants, which are the refractive index $n(\lambda)$ and the extinction coefficient $k(\lambda)$, the reflectivity can be calculated as well. It is given as ${ }^{72}$ 


$$
R=\frac{(1-n)^{2}+k^{2}}{(1+n)^{2}+k^{2}}
$$

Here a larger set of $R$ values relative to others implies a larger refractive index. The published optical constants of InGaP, ${ }^{55} \mathrm{GaAs},{ }^{56}$ and $\mathrm{SiN}_{x},{ }^{57}$ commonly used as the ARC for solar cells, were used for reflectivity calculations, in comparison with those derived from measured reflectance of PQD on GaAs samples with and without COC.

\section{Acknowledgments}

This work was partly performed under the research and development of ultra-high efficiency and low-cost III-V compound semiconductor solar cell modules supported by the National Research and Development Agency, the New Energy and Industrial Technology Development Organization (NEDO), and the Ministry of Economy, Trade, and Industry (METI), Japan, and the Japan Society for the Promotion of Science (JSPS) Grant-in-aid 19J13877. The authors declare no competing financial interests or other potential conflicts of interest.

\section{References}

1. J. F. Geisz et al., "Six-junction III-V solar cells with $47.1 \%$ conversion efficiency under 143 Suns concentration," Nat. Energy 5, 323-335 (2020).

2. M. A. Steiner et al., "Measuring IV curves and subcell photocurrents in the presence of luminescent coupling," IEEE J. Photovoltaics 3(2), 879-887 (2012).

3. D. J. Friedman, J. F. Geisz, and M. A. Steiner, "Analysis of multijunction solar cell currentvoltage characteristics in the presence of luminescent coupling," IEEE J. Photovoltaics 3(4), 1429-1436 (2013).

4. D. Derkacs, D. T. Bilir, and V. A. Sabnis, "Luminescent coupling in GaAs/GaInNAsSb multijunction solar cells," IEEE J. Photovoltaics 3(1), 520-527 (2012).

5. H. Huang et al., "Control of emission color of high quantum yield $\mathrm{CH}_{3} \mathrm{NH}_{3} \mathrm{PbBr}_{3}$ perovskite quantum dots by precipitation temperature," Adv. Sci. 2(9), 1500194 (2015).

6. M. Z. Shvarts et al., "Method for direct measurements of luminescent coupling efficiency in concentrator MJ SCs," AIP Conf. Proc. 1556(1), 147-151 (2013).

7. T. Sogabe et al., "Experimental characterization and self-consistent modeling of luminescence coupling effect in III-V multijunction solar cells," Appl. Phys. Lett. 103(26), 263907 (2013).

8. B. M. F. Yu Jeco et al., "Laser beam induced current (LBIC) mapping of InGaP/GaAs/Ge triple-junction solar cells with luminescence coupling," in Proc. 43rd IEEE Photovoltaic Spec. Conf. (PVSC-43), pp. 1229-1234 (2016).

9. B. M. F. Yu Jeco et al., "Impact of optically nonuniform luminescence coupling effect to the limiting cell conversion efficiency in InGaP/GaAs/Ge triple-junction solar cell," J. Photonics Energy 7(3), 035501 (2017).

10. B. M. F. Yu Jeco et al., "Spatial evaluation of luminescent coupling effect in a currentlimiting subcell of InGaP/GaAs/Ge triple-junction solar cells," in Proc. 7th IEEE World Conf. Photovoltaic Energy Conv. (WCPEC-7), pp. 969-974 (2018).

11. B. M. F. Yu Jeco et al., "Luminescent coupling effect in wafer-bonded III-V on silicon multijunction solar cells," J. Photonics Energy 9(1), 015504 (2019).

12. B. M. F. Yu Jeco et al., "Temperature dependence of wafer-bonded III-V on silicon multijunction solar cells with luminescent coupling effect," J. Photonics Energy 9(1), 015503 (2019).

13. D. F. Marrón et al., "Quantitative determination of luminescent coupling in multijunction solar cells from spectral photovoltage measurements," Phys. Rev. Appl. 6(1), 014001 (2016).

14. B. M. F. Yu Jeco et al., "Analysis of current generation in $\mathrm{InGaP} / \mathrm{GaAs} / \mathrm{Ge}$ triple-junction solar cells with optically non-uniform luminescence coupling effect," in Proc. 33rd Eur. Photovoltaic Solar Energy Conf. (EUPVSEC-33), pp. 1236-1240 (2017).

15. B. M. F. Yu Jeco et al., "Temperature dependence of luminescence coupling effect in InGaP/ GaAs/Ge triple-junction solar cells," J. Photonics Energy 8(2), 022602 (2018). 
16. M. Shvarts et al., "Temperature influence on luminescent coupling efficiency in concentrator MJ SCs," AIP Conf. Proc. 1679, 120003 (2015).

17. J. Yuan et al., "Metal halide perovskites in quantum dot solar cells: progress and prospects," Joule 4, 1160-1185 (2020).

18. X. Ling et al., "Guanidinium-assisted surface matrix engineering for highly efficient perovskite quantum dot photovoltaics," Adv. Mater. 32(26), 2001906 (2020).

19. Y. Wang et al., "Surface ligand management aided by a secondary amine enables increased synthesis yield of $\mathrm{CsPbI}_{3}$ perovskite quantum dots and high photovoltaic performance," Adv. Mater. 32(32), 2000449 (2020).

20. Z. K. Tan et al., "Bright light-emitting diodes based on organometal halide perovskite," Nat. Nanotechnol. 9(9), 687 (2014).

21. H. Cho et al., "Overcoming the electroluminescence efficiency limitations of perovskite light-emitting diodes," Science 350(6265), 1222-1225 (2015).

22. H. Huang et al., "Emulsion synthesis of size-tunable $\mathrm{CH}_{3} \mathrm{NH}_{3} \mathrm{PbBr}_{3}$ quantum dots: an alternative route toward efficient light-emitting diodes," ACS Appl. Mater. Interfaces 7(51), 28128-28133 (2015).

23. Y. H. Kim et al., "Multicolored organic/inorganic hybrid perovskite light-emitting diodes," Adv. Mater. 27(7), 1248-1254 (2015).

24. Z. Shi, X. Li, and C. Shan, "Perovskite quantum dot light-emitting diodes," in Quantum-Dot Based Light-Emitting Diodes, M. S. Ghamsari, Ed., p. 47, IntechOpen (2017).

25. A. Swarnkar et al., "Quantum dot-induced phase stabilization of $\alpha-\mathrm{CsPbI} 3$ perovskite for high-efficiency photovoltaics," Science 354(6308), 92-95 (2016).

26. L. Protesescu et al., "Nanocrystals of cesium lead halide perovskites $\left(\mathrm{CsPbX}_{3}, \mathrm{X}=\mathrm{Cl}, \mathrm{Br}\right.$, and I): novel optoelectronic materials showing bright emission with wide color gamut," Nano Lett. 15(6), 3692-3696 (2015).

27. J. M. Amboy et al., "Cesium lead halide perovskite quantum dot deposition on GaAs substrates by dip-coating," in Proc. 7th IEEE World Conf. Photovoltaic Energy Conv. (WCPEC-7), pp. 467-471 (2018).

28. Y. Wang et al., "All-inorganic colloidal perovskite QDs: a new class of lasing materials with favorable characteristics," Adv. Mater. 27(44), 7101-7108 (2015).

29. Y. Su et al., "Highly controllable and efficient synthesis of mixed-halide $\mathrm{CsPbX}_{3}(\mathrm{X}=\mathrm{Cl}$, $\mathrm{Br}, \mathrm{I})$ perovskite QDs toward the tunability of entire visible light," ACS Appl. Mater. Interfaces 9(38), 33020-33028 (2017).

30. C. Hu et al., "The micropatterning of layers of colloidal quantum dots with inorganic ligands using selective wet etching," Nanotechnology 25(17), 175302 (2014).

31. D. Bryant et al., "Light and oxygen induced degradation limits the operational stability of methylammonium lead triiodide perovskite solar cells," Energy Environ. Sci. 9(5), 1655-1660 (2016).

32. X. Guo et al., "Investigation of moisture stability and PL characteristics of terpineolpassivated organic-inorganic hybrid perovskite," Mater. Renew. Sustain. Energy 5(4), 17 (2016).

33. A. Babayigit et al., "Toxicity of organometal halide perovskite solar cells," Nat. Mater. 15(3), 247 (2016).

34. C. Caddeo et al., "Collective molecular mechanisms in the $\mathrm{CH}_{3} \mathrm{NH}_{3} \mathrm{PbI}_{3}$ dissolution by liquid water," ACS Nano 11(9), 9183-9190 (2017).

35. C. Caddeo et al., "Hydrophilicity and water contact angle on methylammonium lead iodide," Adv. Mater. Interfaces 6(3), 1801173 (2019).

36. C. Müller et al., "Water infiltration in methylammonium lead iodide perovskite: fast and inconspicuous," Chem. Mater. 27(22), 7835-7841 (2015).

37. J. Yang et al., "Investigation of $\mathrm{CH}_{3} \mathrm{NH}_{3} \mathrm{PbI}_{3}$ degradation rates and mechanisms in controlled humidity environments using in situ techniques," ACS Nano 9(2), 1955-1963 (2015).

38. R. K. Misra et al., "Temperature-and component-dependent degradation of perovskite photovoltaic materials under concentrated sunlight," J. Phys. Chem. Lett. 6(3), 326-330 (2015).

39. Y. Dong et al., "Methods of making highly stable perovskite-polymer composites and structures using same," University of Central Florida Research Foundation Inc. (UCFRF), U.S. Patent Application 15/204,171, filed July 7, 2016 (2018). 
Yu Jeco-Espaldon et al.: Application of perovskite quantum dots in carrier redistribution...

40. Y. Dong et al., "Methods of making highly stable perovskite-polymer composites and structures using same," University of Central Florida Research Foundation Inc. (UCFRF), Worldwide Patent Application WO/2018/009530, filed July 7, 2016 (2018).

41. Z. Yu, H. Li, and X. Shan, "Perovskite-polymer composite materials, devices, and methods," The Florida State University Research Foundation, Inc., Worldwide Patent Application WO/ 2019/195517, filed April 9, 2019 (2019).

42. M. Meyns et al., "Polymer-enhanced stability of inorganic perovskite nanocrystals and their application in color conversion LEDs," ACS Appl. Mater. Interfaces 8(30), 19579-19586 (2016).

43. J. He et al., "In situ synthesis and macroscale alignment of $\mathrm{CsPbBr} 3$ perovskite nanorods in a polymer matrix," ACS Nanoscale 10(33), 15436-15441 (2018).

44. Y. Wang et al., "Ultrastable, highly luminescent organic-inorganic perovskite-polymer composite films," Adv. Mater. 28(48), 10710-10717 (2016).

45. R. R. Lamonte and D. McNally, "Cyclic olefin copolymers," Adv. Mater. Processes 159(3), 33-36 (2001).

46. T. Nielsen et al., "Nanoimprint lithography in the cyclic olefin copolymer, Topas ${ }^{\circledR}$, a highly ultraviolet-transparent and chemically resistant thermoplast," J. Vac. Sci. Technol. B: Microelectron. Nanometer Struct. Process. Meas. Phenomena 22(4), 1770-1775 (2004).

47. S. Baek et al., "Development of mixed-cation $\mathrm{Cs}_{x} \mathrm{Rb}_{1-x} \mathrm{PbX}_{3}$ perovskite quantum dots and their full-color film with high stability and wide color gamut," Adv. Opt. Mater. 6(15), 1800295 (2018).

48. “Topas ${ }^{\circledR}$ Advanced Polymers "Specification sheet-Topas ${ }^{\circledR}$ COC Polymers," https://topas .com/sites/default/files/PRODUCTS-E-13.06.19.pdf.

49. S. K. Tripathy, "Refractive indices of semiconductors from energy gaps," Opt. Mater. 46, 240-246 (2015).

50. D. Grosso, "How to exploit the full potential of the dip-coating process to better control film formation," J. Mater. Chem. 21, 17033 (2011).

51. B. D. Chernomordik et al., "Quantum dot solar cell fabrication protocol," Chem. Mater. 29(1), 189-198 (2017).

52. ASTM Standard Reference Spectra G173-03, Standard Tables for Reference Solar Spectral Irradiances: direct Normal and Hemispherical on $37^{\circ}$ Tilted Surface, ASTM International, West Conshohocken, Pennsylvania (2012).

53. J. H. Ermer et al., "Status of C3MJ+ and C4MJ production concentrator solar cells at spectrolab," IEEE J. Photovoltaics 2(2), 209-213 (2012).

54. T. Takamoto et al., "InGaP/GaAs-based multijunction solar cells," Prog. Photovoltaics: Res. Appl. 13(6), 495-511 (2005).

55. M. Schubert et al., "Optical constants of $\mathrm{Ga}_{\mathrm{x}} \mathrm{In}_{1-\mathrm{x}} \mathrm{P}$ lattice-matched to GaAs," J. Appl. Phys. 77(7), 3416-3419 (1995).

56. G. E. Jellison, Jr., "Optical functions of GaAs, GaP, and Ge determined by two-channel polarization modulation ellipsometry," Opt. Mater. 1(3), 151-160 (1992).

57. M. R. Vogt, "Development of physical models for the simulation of optical properties of solar cell modules," Doctoral dissertation, Technische Informationsbibliothek (TIB) (2016).

58. Y. Zhang et al., "Time-dependent photoluminescence blue shift of the quantum dots in living cells: effect of oxidation by singlet oxygen," J. Am. Chem. Soc. 128(41), 13396-13401 (2006).

59. W. Mi et al., "Temperature dependent synthesis and optical properties of CdSe quantum dots," Ceram. Int. 38(7), 5575-5583 (2012).

60. N. G. Anderson et al., "Optical characterization of pseudomorphic $\operatorname{In}_{x} \mathrm{Ga}_{1-x}$ As-GaAs single quantum well heterostructures," J. Appl. Phys. 60(7), 2361-2367 (1986).

61. M. L. Huang et al., "Surface passivation of III-V compound semiconductors using atomiclayer-deposition-grown $\mathrm{Al}_{2} \mathrm{O}_{3}$," Appl. Phys. Lett. 87(25), 252104 (2005).

62. S. M. George, "Atomic layer deposition: an overview," Chem. Rev. 110(1), 111-131 (2009).

63. J. Schmidt et al., "Surface passivation of high-efficiency silicon solar cells by atomic-layerdeposited $\mathrm{Al}_{2} \mathrm{O}_{3}$," Prog. Photovoltaics: Res. Appl. 16(6), 461-466 (2008).

64. C. L. Hinkle et al., "GaAs interfacial self-cleaning by atomic layer deposition," Appl. Phys. Lett. 92(7), 071901 (2008). 
65. P. Poodt et al., "High-speed spatial atomic-layer deposition of aluminum oxide layers for solar cell passivation," Adv. Mater. 22(32), 3564-3567 (2010).

66. J. Benick et al., "Thermal stability of the $\mathrm{Al}_{2} \mathrm{O}_{3}$ passivation on p-type silicon surfaces for solar cell applications," Physica Status Solidi (RRL)-Rapid Res. Lett. 3(7-8), 233-235 (2009).

67. P. Saint-Cast et al., "High-efficiency c-Si solar cells passivated with ALD and PECVD aluminum oxide," IEEE Electron Device Lett. 31(7), 695-697 (2010).

68. J. A. Van Delft, D. Garcia-Alonso, and W.M.M. Kessels, "Atomic layer deposition for photovoltaics: applications and prospects for solar cell manufacturing," Semicond. Sci. Technol. 27(7), 074002 (2012).

69. G. Dingemans and W. M. M. Kessels, "Status and prospects of $\mathrm{Al}_{2} \mathrm{O}_{3}$-based surface passivation schemes for silicon solar cells," J. Vac. Sci. Technol. A: Vac. Surf. Films 30(4), 040802 (2012).

70. F. Capasso and G. F. Williams, "A proposed hydrogenation/nitridization passivation mechanism for GaAs and other III-V semiconductor devices, including InGaAs long wavelength photodetectors," J. Electrochem. Soc. 129(4), 821-824 (1982).

71. W. Nie et al., "High-efficiency solution-processed perovskite solar cells with millimeterscale grains," Science 347(6221), 522-525 (2015).

72. J. Mistrik et al., "Chapter 3-Optical properties of electronic materials: fundamentals and characterization," in Springer Handbook of Electronic and Photonic Materials, S. Kasap and P. Capper, Eds., Springer Handbooks, Springer, Cham (2017).

Bernice Mae Yu Jeco-Espaldon received her BS degree in electronics and communications engineering from the University of Santo Tomas, Philippines, in 2011 and her MS degree in electrical engineering and information systems and her $\mathrm{PhD}$ in advanced interdisciplinary studies from The University of Tokyo (UT) in 2017 and 2020, respectively. She is a postdoctoral research fellow in the Department of Urban Engineering, Graduate School of Engineering, UT, Japan, and an adjunct lecturer at the University of Santo Tomas, Philippines. Her current research interests include concentrator photovoltaics, UV disinfection, and multi-faceted studies on off-the-grid water disinfection. She is an associate member of the National Research Council of the Philippines.

Haibin Wang is currently a research fellow in the Research Center for Advanced Science and Technology (RCAST) at the University of Tokyo (UT), Japan. He received his $\mathrm{PhD}$ from Graduate School of Arts and Sciences at the University of Tokyo, Japan in 2012. His main research interest focuses on the nanomaterials and nanostructures fabrication to develop emerging thin film photovoltaics and optoelectronic devices.

Achilles E. Espaldon received his BS degree in chemical engineering from the University of Santo Tomas, Philippines in 2001 and his MS degree in chemical engineering from the National University of Singapore (NUS) in 2010. He is a PhD candidate at the Department of Advanced Interdisciplinary Studies, the University of Tokyo (UT), Japan. His research interests include UV and chemical disinfection, water treatment, development of new medical devices, and pharmaceuticals.

Takaya Kubo is a project professor of the Research Center for Advanced Science and Technology, The University of Tokyo (UTokyo). He was educated at Tokyo Institute of Technology (MA 1989, PhD 1992). His doctoral research was concerned with the low lying excited states of conjugated polymers. He was working at the Central Technical Research Laboratory of Nippon Oil Corporation (currently, ENEOS Corporation) between 1992 and 2006. In 2006, he was appointed a project associate professor of UTokyo. In 2011, he was appointed to his current position. His research interest includes low-dimensional materials such as colloidal quantum dots, and transparent wide-bandgap oxides, and also solution-processed photovoltaics devices.

Hiroshi Segawa: Biography is not available. 
Nazmul Ahsan received his BE degree in electrical and electronic information engineering from Toyohashi University of Technology, Japan, in 1997 and his MS degree and $\mathrm{PhD}$ in electronic engineering from the University of Tokyo (UT), Japan, in 1999 and 2002, respectively. He then held a Japan Science and Technology Agency research fellowship at UT and worked on light and electric field control of ferromagnetism using III-V heterostructures. He is currently a project associate professor at the Research Center for Advanced Science and Technology (RCAST), Utah, USA. His research interests include ultra-high-efficiency photovoltaic devices, spintronic devices, and molecular beam epitaxy of compound semiconductors. His articles have more than 1000 citations (Google Scholar).

Yoshitaka Okada received his bachelor's degree in electronic and electrical engineering from the University of London in 1984 and his master's degree and $\mathrm{PhD}$ in electronic engineering from the University of Tokyo in 1987 and 1990, respectively. He is currently a professor at the RCAST of the University of Tokyo. He was appointed a visiting assistant professor at Stanford University, 1995 to 1996, and a visiting fellow at the Imperial College London in 2006 and at the Cavendish Laboratory of the University of Cambridge in 2015. His research interests include epitaxial crystal growth of III-V-N dilute nitrides, III-Vs on $\mathrm{Si}$, and low-dimensional quantum nanostructures for applications to high efficiency multi-junction and intermediate-band solar cells. 